\title{
JOGOS MATEMÁTICOS E MEDIAÇÃO DOCENTE
}

\author{
JUEGOS MATEMÁTICOS Y MEDIACIÓN DOCENTE
}

MATHEMATICAL GAMES AND TEACHING MEDIATION

Patrícia PEREIRA ${ }^{1}$

RESUMO: O artigo trata de ações de ensino planejadas intencionalmente com o uso de jogos como Situação Desencadeadora de Aprendizagem visando a internalização de conhecimentos teóricos por meio da ação e reflexão decorrentes da mediação docente. Os participantes foram 8 crianças do $2^{\circ}$ ano do Ensino Fundamental, selecionadas pela professora da turma. O procedimento investigativo tomou como referência o uso de uma Atividade Orientadora de Ensino (AOE), por meio de Situações Desencadeadoras de Aprendizagem (SDAs), verificando se o jogo, quando utilizado sob a abordagem histórico-cultural, desencadeia a aprendizagem de alguns conceitos inerentes às operações de adição e subtração. Para tanto, utilizaram-se os jogos CUBRA A SOMA e FECHE A CAIXA. O estudo consistiu em cinco Atividades de Ensino com cada jogo. Os resultados indicaram que as mediações, associadas à motivação das crianças, durante a Atividade Orientadora de Ensino (AOE), podem proporcionar o desenvolvimento das funções psíquicas superiores.

PALAVRAS-CHAVE: Jogos. Adição e subtração. Mediação.

RESUMEN: El artículo discute acciones educativas planeados intencionalmente con el uso de juegos como Situación de Aprendizaje con el objetivo de internalización de conocimientos teóricos a través de la acción y la reflexión como resultado de la mediación. Los participantes fueron 8 niños de $2^{\circ}$ año de primaria, seleccionados por ella profesora de la clase. El procedimiento de investigación tomó como referencia el uso de una guía de enseñanza actividad, a través de Situaciones de Aprendizaje, para verificar se el juego, cuando se utiliza bajo el enfoque histórico cultural, dispara aprender algunos conceptos inherentes a las operaciones de suma y resta. Con este fin, los juegos usados fueron CUBRA A SOMA y FECHE A CAIXA. El estudio consistió en cinco actividades de enseñanza con cada juego. Los resultados indicaron que las mediaciones, asociadas con la motivación de los niños, durante la actividad docente $(A O E)$, pueden proporcionar el desarrollo de funciones psicológicas superiores.

PALABRAS CLAVE: Juegos. Suma y resta. Mediación.

\footnotetext{
${ }^{1}$ Universidades Federal de São Carlos (Ufscar), São Carlos - SP - Brasil. Mestre em Educação pelo Programa de Pós-graduação Profissional em Educação. Especialista em Ética, Valores e Saúde na Escola pelo Programa de Pós-graduação da Universidade de São Paulo (USP/UNIVESP). Docente da Prefeitura Municipal de São Carlos (PMSC). Docente da Secretaria Estadual de Educação de São Paulo (SEE-SP). E-mail: patricinha.pereira@yahoo.com.br.
} 
ABSTRACT: The article discusses educational actions planned intentionally with the use of games like Trigger learning Situation for internalisation of theoretical knowledge through the action and reflection as a result of mediation. Participants were 8 children of 2 nd year of elementary school, selected by the teacher of the class. The investigative procedure took as a reference using a Guiding teaching Activity, through Being Learning Situations, verifying that the game, when used under the historical-cultural approach, triggers learning some concepts inherent in the operations of addition and subtraction. To this end, the games used CUBRA A SOMA and FECHE A CAIXA. The study consisted of five teaching activities with each game. The results indicated that the mediations, associated with the motivation of children, during the Teaching activity, can provide the development of highter psychological functions.

KEYWORDS: Games. Addition and subtraction. Mediation.

\section{Introdução}

O presente trabalho aborda como jogos matemáticos podem constituir-se em importantes aliados do ambiente escolar, desde que haja a intencionalidade docente articulando a atividade de ensino e a atividade de aprendizagem.

A intenção deste estudo parte do pressuposto que é de suma importância a adoção de uma prática pedagógica diversificada, por meio da qual a mediação pode possibilitar às crianças vivências que despertem o interesse em aprender matemática.

Logo, buscou-se identificar se o uso de jogos, com o apoio da mediação, favorece a apropriação de conceitos envolvidos nas operações de adição e subtração em um grupo constituído por 8 crianças do $2^{\circ}$ ano do Ensino Fundamental, de uma Escola Estadual de uma cidade situada no interior do estado de São Paulo. Assim, optou-se por um estudo de caso por representar um estudo profundo de poucos objetos, de forma a permitir amplo e detalhado conhecimento da situação, e pelo fato de essa modalidade de pesquisa estar sendo usada na Educação Matemática para investigar questões de aprendizagem dos alunos (PONTE, 2006).

Assim, primeiramente procuramos descrever, brevemente, o jogo como Situação Desencadeadora de Aprendizagem. Em seguida, apresentamos o jogo associado às operações de adição e subtração e o papel da mediação na aprendizagem, abordando a importância do planejamento para o uso desse recurso em aulas de Matemática e um breve relato sobre os jogos utilizados. Por fim, discutimos os resultados obtidos e apresentamos nossas considerações finais tendo como referência a abordagem Histórico-Cultural. 


\section{O jogo como situação desencadeadora de aprendizagem}

O jogo como Situação Desencadeadora de Aprendizagem (SDA) deve ter presente a intenção do professor: propiciar a aprendizagem, seja de um conteúdo ou de uma habilidade. O jogo pode mobilizar as crianças para a aprendizagem de determinado conceito matemático, desde que seja desenvolvido a partir de um conjunto de necessidades e motivos. Além disso, quando o jogo é utilizado com intenção pedagógica, apresenta-se como importante elemento da atividade de ensino, pois possibilita a proposição de problemas diversos. De fato, Moura et al. (2010, p. 105) esclarecem que devermos considerar "a possibilidade de o jogo colocar a criança diante de uma situação-problema semelhante à vivenciada pelo homem ao lidar com conceitos Matemáticos".

Assim, com intencionalidade educativa, o jogo pode representar caminhos para as crianças superarem as dificuldades de aprendizagem de conceitos matemáticos. Para tanto, precisamos tomar o jogo como recurso de ensino, de modo que assuma:

[...] novas dimensões, e é isto que nos obriga a classificá-lo considerando o papel que pode desempenhar no processo de aprendizagem. O jogo pode, ou não, ser jogo no ensino. [...] $\mathrm{O}$ jogo deve ser jogo do conhecimento, e isto é sinônimo de movimento do conceito e do desenvolvimento (MOURA, 1991, p. 49, grifo nosso).

No ensino da matemática, o jogo apresenta-se como um importante recurso pedagógico, não apenas por representar prazer e descontração para as crianças, mas por possibilitar a formação de conhecimentos (NACANALLO; MORI, 2008).

Segundo Moretti e Souza,

O jogo ou a brincadeira pode constituir-se como importante recurso metodológico nos processos de ensino e de aprendizagem, se considerado de forma intencional e em relação com o conceito que se pretende ensinar. No caso da Matemática, é possível planejar situações nas quais, por meio da brincadeira desencadeada por jogos ou por histórias, as crianças se deparem com as necessidades de contar, registrar contagens, socializar registros, organizar dados (2015, p. 32).

Ao jogar, a criança potencializa sua possibilidade de aprender e de se apropriar de novos conhecimentos, pois se coloca em um nível acima da sua aprendizagem atual. Segundo Assis et al (2012), um jogo será desafiador se solicitar ações e reflexões um pouco acima das possibilidades atuais das crianças, e despertar o interesse para querer superar os obstáculos. Por outro lado, a agilidade mental, a iniciativa e a curiosidade, 
presentes nas situações favorecidas pelo jogo, estendem-se de forma natural para a vida da criança, inclusive na escola.

Os jogos apresentam, portanto, um aspecto relevante por proporcionarem desafios às crianças, ocasionando interesse e prazer, ou seja, motivando a aprendizagem. Então, é de suma importância esse recurso fazer parte do cotidiano escolar, desde que o professor tenha uma intencionalidade educativa e potencialize a aprendizagem dos conceitos científicos tendo como referência a necessidade da mediação e da motivação.

\section{O jogo e as operações de adição e subtração}

As crianças podem apropriar-se de conceitos envolvidos nas operações de adição e subtração, por meio do uso de jogos em que jogam juntas, seguindo "regras preestabelecidas, que conduzem a um ou vários clímax e nos quais os jogadores podem ser interdependentes, opostos ou cooperativos, propiciando a elaboração de estratégias" (ASSIS et al, 2012, p. 52).

Os jogos podem possibilitar às crianças vivenciarem situações-problema relacionadas às ideias das operações de adição e subtração (juntar, acrescentar, tirar e comparar) e, dessa forma, criar, socializar e analisar diferentes estratégias para resolver os problemas envolvendo a contagem, o registro de contagens, o cálculo mental, o cálculo escrito e a estimativa. Ao jogar, a criança vivencia situações que necessitam de soluções, de raciocínio lógico-dedutivo e possibilitam a ela realizar diferentes contagens, registros e cálculos. A comparação entre as diferentes soluções encontradas pelas crianças pode ser desencadeadora da aprendizagem das ideias envolvidas nas operações de adição e subtração, na medida em que são utilizadas diferentes estratégias na busca das soluções dos problemas a serem propostos a elas.

Os jogos CUBRA A SOMA e FECHE A CAIXA, adotados neste estudo, tiveram a finalidade de as crianças aprenderem a relacionar ideias aditivas e subtrativas, identificando a operação que resolve cada situação. A articulação entre adição e subtração é fundamentada pelo princípio de que a apropriação desses conceitos relaciona-se com o sentido atribuído a eles em diferentes contextos, com suas múltiplas relações internas, e, também, pelas relações estabelecidas com outros conceitos (MORETTI; SOUZA, 2015). 
Assim, situações de adição e subtração devem ser abordadas ao mesmo tempo em que se trabalha com o significado do número natural, sem a preocupação da criança registrar, de imediato, a forma convencional, por meio de algoritmos, mas com a intenção de compreender as ideias associadas a essas situações. No início da aprendizagem das ideias dessas operações, as situações podem ser apresentadas oralmente, por escrito, por figuras, e até por jogos, a fim de as crianças aprenderem a estabelecer relações.

Segundo Nunes et al (2009), para verificar se a criança entende a composição aditiva de números, é necessário criar situações em que precise contar unidades de valores diferentes e coordená-las em uma quantia única, pois, embora seja capaz de contar objetos usando a sequência numérica, não consegue compreender as adições subentendidas na contagem e sobrecontagem.

Assim, é muito importante que os professores busquem compreender as dificuldades no aprendizado da adição e subtração, e procurem criar atividades de ensino em sala de aula que possibilitem superar essas dificuldades. Diante disso, para a formação do conhecimento aditivo, é necessário o ensino organizar-se de modo à criança conseguir apropriar-se desse conhecimento. Assim, Moura et al (2010) defendem que se deve partir dos conceitos gerais e não dos casos particulares do conhecimento, buscando a origem e a essência do conceito.

Considerando que os processos de funcionamento mental do homem não são fornecidos apenas pela cultura, mas também por meio da mediação simbólica, é preciso, então, criar experiências que permitam às crianças desenvolverem suas habilidades de contar, pois apenas a repetição dos procedimentos de contagem não garante a compreensão dos conceitos matemáticos. Para Vigotsky (2009, p. 156),

[...] a formação de conceitos é um processo de caráter produtivo e não reprodutivo, em que um conceito surge e se configura no curso de uma operação complexa voltada para a solução de algum problema, e que só a presença de condições externas e o estabelecimento mecânico de uma ligação entre a palavra e o objeto não são suficientes para a criação de um conceito.

Em consideração a essas constatações, os jogos CUBRA A SOMA e FECHE A CAIXA foram utilizados de forma a proporcionar situações que envolvessem as ideias da adição e subtração. Tomamos, como ponto de partida, a necessidade de contagem e sobrecontagem de quantidades representadas nas faces superiores dos dados. Propusemos problemas e observamos as estratégias utilizadas pelas crianças na solução 
dos problemas propostos. Procuramos atribuir um caráter produtivo às situações propostas, no sentido de envolver as crianças na busca da solução de problemas envolvendo as ideias da adição e da subtração.

\section{O papel da mediação e dos jogos na aprendizagem}

O processo de mediação não se restringe à mediação docente. A abordagem histórico-cultural considera que a atividade humana é mediada por signos culturais, tais como: linguagens, objetos, tecnologias, meios de comunicação, convenções, entre outros.

Dentre esses signos, “a linguagem é o elemento mais decisivo na sistematização da percepção; na medida em que as palavras são, elas próprias, produto do desenvolvimento sócio-histórico, tornam-se instrumentos para a formulação de abstrações e generalizações" (LURIA, 1994, p. 67).

Diante disso, a mediação é fundamental na abordagem histórico-cultural, pois é por meio dos instrumentos (cuja função é regular as ações sobre os objetos) e dos signos (que regulam as ações sobre o psiquismo das pessoas) que os processos de funcionamento psicológico são fornecidos pela cultura. Para Vigotsky (2009), os sistemas simbólicos (entendidos como sistemas de representação da realidade), especialmente a linguagem, funcionam como elementos mediadores que permitem a comunicação entre os indivíduos, o estabelecimento de significados (para diversos eventos, objetos, situações, etc.) compartilhados por um determinado grupo cultural; bem como a percepção e a interpretação dos objetos, eventos e situações do mundo circundante.

Na escola, o professor faz uso de elementos mediadores para criar condições, de modo à aprendizagem tornar-se efetiva. Para tanto, pode utilizar práticas pedagógicas intencionalmente planejadas, a fim de seus alunos apropriarem-se dos conhecimentos e conceitos científicos sistematizados nos conteúdos curriculares. Nessa ação, a mediação do professor põe-se entre as crianças e o conhecimento para possibilitar a aprendizagem.

Segundo Kishimoto (2000), muitos professores, na tentativa de mudar o ensino e torná-lo mais atraente, acabaram incorporando o uso de jogos nas suas salas de aula acreditando que sua utilização levaria à compreensão de conceitos matemáticos. 
Para a abordagem histórico-cultural, que relaciona o processo de aprendizagem às interações sociais, embora muitos conceitos matemáticos sejam usados pelas crianças no cotidiano, nas suas práticas sociais, isso não pressupõe que o simples uso seja garantia de apreensão conceitual sob o ponto de vista teórico.

Ao jogar, a criança tem a tendência de usar seus conhecimentos cotidianos para resolver as situações apresentadas, recorrendo a estratégias próprias. Contudo, considerando que a aprendizagem dos conceitos científicos não ocorre espontaneamente, cabe ao professor organizar e proporcionar atividades de ensino, nas quais as crianças sintam a necessidade do conceito que se quer ensinar para resolver situações-problema. Além disso, precisam sentir-se motivadas a aprender o conceito que se pretende ensinar. A mediação do professor deve permitir a elas superar a superficialidade do contexto e explorar as características essenciais dos conceitos em questão.

Desse modo, é importante que o professor saiba quais conceitos matemáticos podem ser desenvolvidos no jogo a ser adotado e como podem ser desenvolvidos, de maneira a favorecer a apropriação desses conceitos: "O jogo é um instrumento cultural. É instrumento e, enquanto tal, para desencadear desenvolvimento e aprendizagem, exige a mediação do educador" (GIARDINETTO; MARIANI, 2007, p. 3).

Diante disso, o ensino deve ter um significado, um sentido para as crianças, de maneira a potencializar a aprendizagem. A mediação pode favorecer a atribuição de significado e sentido aos conteúdos a serem assimilados pelas crianças.

Dessa maneira, ao refletir sobre uma organização de ensino para crianças do $2^{\circ}$ ano do Ensino Fundamental, cuja faixa etária compreende alunos de 7 a 8 anos, tendo como referência a abordagem histórico-cultural, não podemos deixar de considerar o papel da mediação e a importância da motivação das crianças nos processos educativos.

\section{A importância do planejamento}

A utilização de jogos na sala de aula necessita planejamento. Antes de serem apresentados às crianças, é preciso analisar sua viabilidade para os objetivos almejados, bem como o tempo previsto para a sua utilização.

É importante que as regras sejam compreendidas, a fim de as crianças aprimorarem suas estratégias de solução de problemas que podem ser proporcionados por meio do uso de jogos. Por isso, o uso desse recurso demanda intencionalidade e 
regularidade nas aulas, não devendo ser realizado eventualmente ou com pouco tempo, para se tornar, efetivamente, uma atividade de aprendizagem.

Organizar a turma em grupos e favorecer a interação entre as crianças são ações essenciais no trabalho com o uso de jogos na escola. Ao jogar, a criança precisa realizar negociações, considerar a opinião do colega e argumentar sobre a sua posição quando as formas de resolver determinados problemas são distintas.

Parte-se da concepção de todas as crianças poderem aprender a partir de um ambiente rico em situações que possibilitem a apropriação de conceitos e representações simbólicas. Os jogos apresentam-se como recurso que auxilia a aprendizagem na medida em que favorece o avanço contínuo das crianças, em seu próprio ritmo, posto ter tempos e modos diferentes para aprender.

Priorizando processos pedagógicos que incentivam a curiosidade, a criatividade, o raciocínio e o pensamento crítico, torna-se imprescindível a problematização de atividades de ensino de modo a permitir o desenvolvimento do pensamento da criança pela análise, interpretação e compreensão de relações matemáticas; que podem ser favorecidas pelo uso de jogos, de forma a desenvolver atitudes positivas com relação à aprendizagem da matemática.

Do mesmo modo, é essencial considerar que os erros e os acertos colaboram na aprendizagem de conceitos matemáticos. Compreender os erros e acertos realizados pelas crianças é tarefa primordial dos professores, visto que podem oferecer pistas de como e o quê elas pensaram, quais caminhos percorreram para solucionar determinado problema, as estratégias utilizadas na obtenção da solução, bem como o que ainda não foi compreendido.

Essa tarefa essencial do professor torna-se mais concreta na medida em que passa a considerar o papel mediador exercido não só por ele, mas também pelo conhecimento matemático e os recursos que utiliza.

Esse pode ser o ponto de partida tanto para o professor quanto para as crianças elaborarem novas estratégias de solução de problemas. Assim, cabe ao professor criar estratégias, a fim de as crianças poderem partilhar inquietações, apropriações, sentimentos e pensamentos.

\section{Os jogos}


Os jogos integram-se na cultura das sociedades, podendo um mesmo jogo apresentar diferentes variações. Normalmente, a estrutura dos jogos mantém-se, porém, as regras, os materiais, as figuras, os gestos, as interações e outros elementos são influenciados pelo momento histórico e características sociais, assim, apresentaremos brevemente os jogos utilizados neste estudo.

O jogo CUBRA A SOMA (figura 1) auxilia as crianças a:

- associar uma quantidade ao símbolo que a representa;

- compreender ideias da adição tal como a ação de acrescentar uma quantidade à outra;

- apropriar os fatos fundamentais da adição, os quais favorecem o desenvolvimento do cálculo mental e do pensamento matemático envolvido nas operações de adição e subtração;

- realizar o cálculo mental e/ou escrito.

Figura 1: Jogo Cubra a Soma

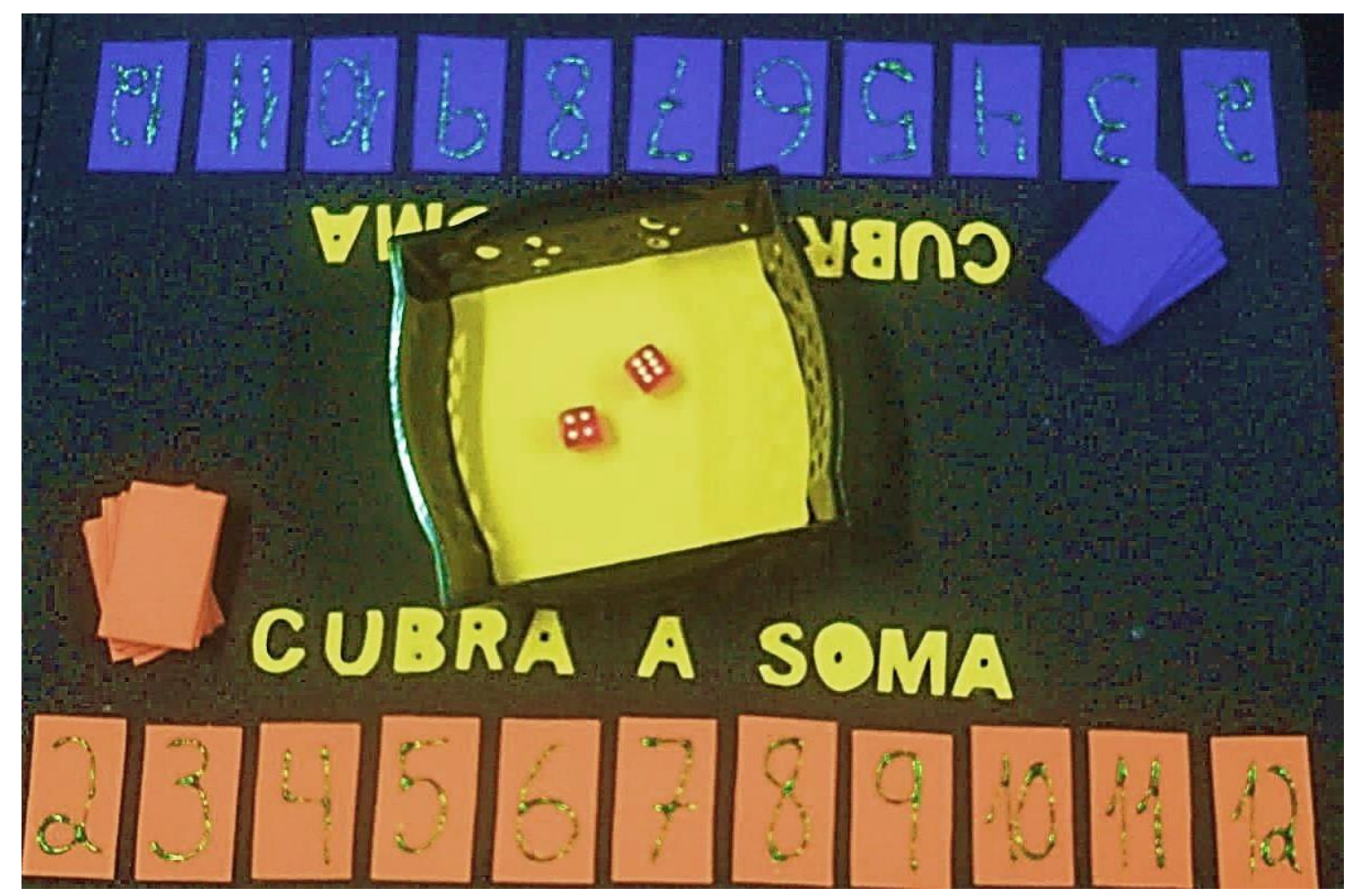

Fonte: Jogo Cubra a Soma (2016)

O jogo FECHE A CAIXA é um antigo jogo de dados, com mais de duzentos anos, originário da Normandia (região litorânea da França). Era disputado por marinheiros, sendo ainda hoje bastante apreciado em vários países da Europa e da África Central. Por não ser muito difícil de jogar e confeccionar, os marinheiros 
passavam o tempo jogando e desenvolvendo estratégias de jogo, as quais envolviam muita matemática e raciocínio lógico (LÁZARO; TANAKA; RODRIGUES, 2013).

Recomenda-se o uso desse jogo com crianças que ainda não dominam cálculos simples de memória. Deve ser jogado com certa frequência, podendo ser aplicado em qualquer nível de ensino com as adequações necessárias.

O intuito do jogo FECHE A CAIXA (figura 2) é desenvolver o raciocínio, o cálculo mental e a compreensão de conceitos de adição e subtração, tais como, perceber as diferentes possibilidades de adicionar quantidades para obter um mesmo resultado. $\mathrm{O}$ objetivo desse jogo é fechar o maior número possível de casas e perder o mínimo de pontos em cada rodada, a fim de não parar de jogar. Esse jogo auxilia os alunos a:

- compreender a ideia da adição como a ação de acrescentar uma quantidade à outra;

- construir os fatos fundamentais da adição. A fluência com fatos fundamentais favorece o desenvolvimento do cálculo mental e a apropriação de outros conhecimentos matemáticos;

- compreender a ideia da subtração como a ação de tirar uma quantidade da outra;

- desenvolver estratégias para a solução de problemas.

Figura 2: Jogo Feche a Caixa

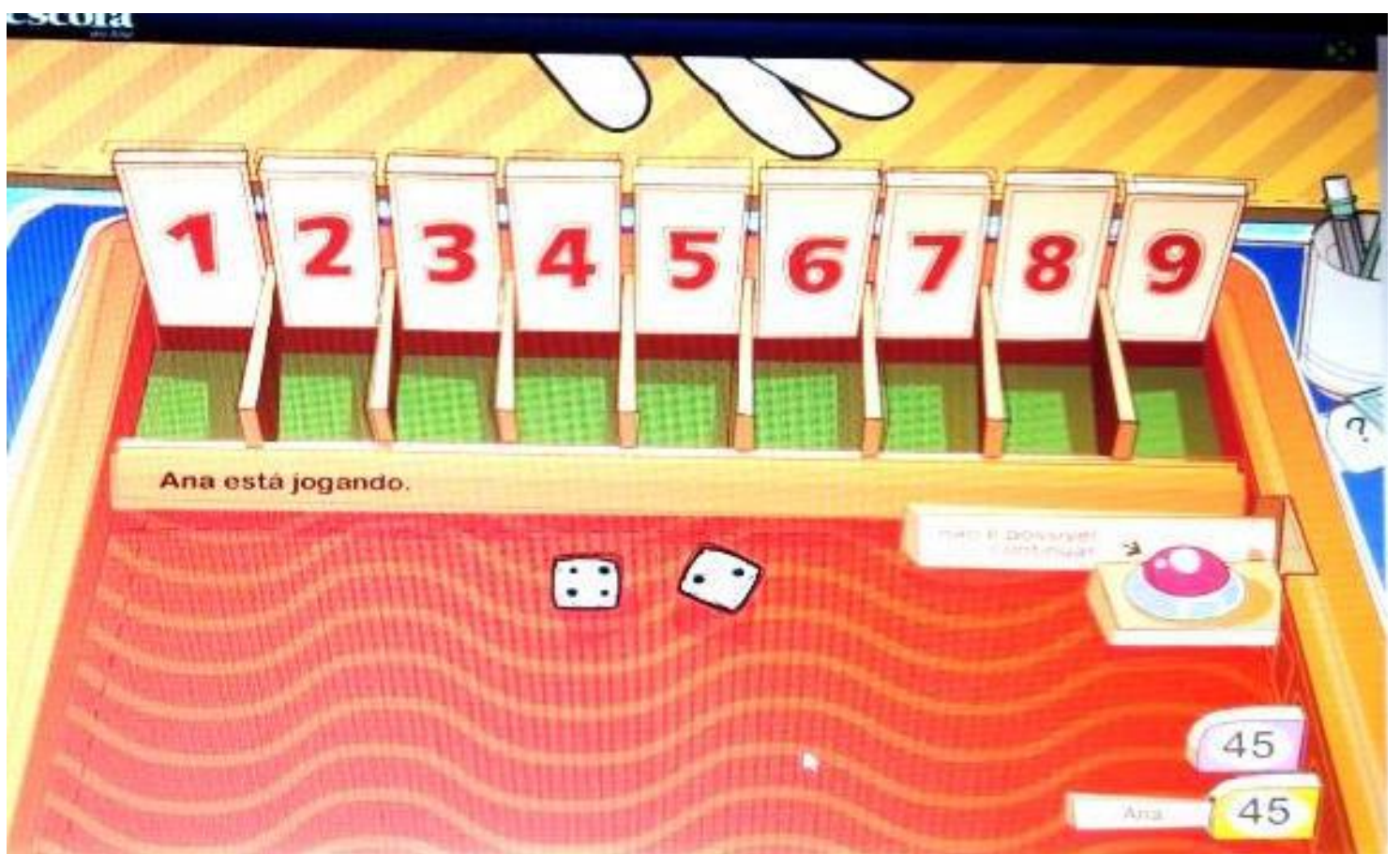

Fonte: Jogo Feche a Caixa 
Ressaltamos que, além dos jogos, o planejamento de Atividades de Ensino (AEs) pode possibilitar o desenvolvimento de estratégias de contagem, sobrecontagem e possibilidades de adição, por meio da Situação Desencadeadora de Aprendizagem (SDA), através de situações-problema associadas à "gênese do conceito" (MOURA et al., 2010, p.103), de maneira que as crianças se aproximem do conceito, com "um conhecimento de qualidade nova" (MOURA et al, 2010, p. 97).

Essas Atividades de Ensino (organizadas intencionalmente) constituem-se em situações baseadas em objetivos de ensino e traduzem-se em conteúdos a serem apropriados pelas crianças no espaço de aprendizagem (a sala de aula). E ainda, estando motivadas, essas crianças interagem com as demais, segundo suas potencialidades, possibilitando o seu desenvolvimento para outro nível de compreensão do conceito (MOURA et al, 2010).

Segundo Moura et al (2010, p. 103), a Situação Desencadeadora de Aprendizagem (SDA) "é organizada pelo professor tomando-se por base os seus objetivos de ensino que, como dissemos, se traduzem em conteúdos a serem apropriados pelos estudantes no espaço de aprendizagem". Considerando a escola como espaço de aprendizagem, as ações do professor podem mobilizar e motivar as crianças na apropriação de conceitos, promovendo interações com outras crianças, de acordo com suas potencialidades, objetivando outro nível de compreensão dos conceitos em questão.

Destacamos ainda que o uso de uma Situação Desencadeadora de Aprendizagem (SDA) pressupõe que o professor resgate a necessidade do conceito, bem como a maneira pela qual foram aparecendo os problemas e as necessidades humanas em determinadas atividades.

Considerando a intencionalidade da aprendizagem e o processo de apropriação dos conceitos envolvendo as operações de adição e subtração, por meio de Atividades de Ensino com o uso dos jogos CUBRA A SOMA e FECHE A CAIXA, podemos considerar que estas ações constituem uma Situação Desencadeadora de Aprendizagem (SDA).

\section{Análise dos jogos utilizados}

$\mathrm{O}$ presente estudo procurou investigar se o jogo, quando utilizado sob a abordagem histórico-cultural, desencadeia a aprendizagem das operações de adição e 
subtração, diante do interesse de verificar o papel da mediação e da motivação no ensino e aprendizagem da matemática.

Analisaram-se as reações das crianças captadas por meio de filmagens e gravações em áudio, considerando conceitos da abordagem histórico-cultural, com foco nas mediações e motivações, observando o que está, de fato, nas falas, nos gestos, tendo como meta obter indicações da ocorrência (ou não) da aprendizagem de conceitos envolvidos nas operações de adição e subtração.

Consideramos a mediação e a motivação como elementos de análise por serem condições fundamentais para desencadear a aprendizagem. Observamos a motivação das crianças e as condições criadas pela pesquisadora para a apropriação dos conceitos abordados, visto que as necessidades, os motivos, as ações e as operações mentais constituem-se como elementos característicos da AOE, pois permitem que seja elemento de mediação entre as atividades de ensino e de aprendizagem.

Esses elementos de análise ressaltam a importância de considerar os motivos das crianças para a realização das atividades de aprendizagem, visto não se poder pensar em uma atividade de aprendizagem sem motivo, pois uma atividade não motivada não desperta o interesse na criança, tampouco na atribuição de sentido àquilo que está por aprender.

Buscou-se observar não somente se as crianças estavam motivadas ou não durante as situações de ensino, mas também o que as motivaram (ou não) para a aprendizagem. Para isso, consideramos os três grupos principais de motivos para a atividade de aprendizagem: os sociais, os relacionados à própria aprendizagem e os cognitivos.

Neste estudo, consideramos que os motivos de aprendizagem e os cognitivos originam-se de uma atividade de aprendizagem. Igualmente, relacionam-se aos motivos sociais, visto que a mediação influencia a motivação, por meio do uso da linguagem, sendo esses aspectos fundamentais para o desenvolvimento e a apropriação de conceitos.

Com relação à mediação, observou-se tanto a mediação da pesquisadora quanto as mediações possibilitadas pelo jogo e o conhecimento matemático, bem como as interações ocorridas entre as crianças.

\section{Considerações finais}


O estudo possibilitou-nos perceber que a maneira como a criança desenvolve alguns dos conceitos matemáticos envolvidos nas operações de adição e subtração relaciona-se com os motivos e as necessidades de apropriação desses conceitos. Cabe ao professor saber como despertar esse "querer aprender" nas crianças. Para tanto, ao ensinar determinado conceito matemático, o professor deve indicar uma necessidade (apropriação da cultura) e um motivo real (apropriação do conhecimento historicamente construído).

Defendemos que a mediação contribui para as crianças internalizarem ações mentais envolvidas na formação de conceitos matemáticos. Quanto às condições para que isso se desenvolva, compete ao professor a seleção e a organização de materiais adequados, bem como a intenção de atrair a atenção das crianças para a aprendizagem.

$\mathrm{O}$ jogo, quando planejado e organizado intencionalmente, pode criar possibilidades de desenvolvimento das funções intelectuais, propondo ações e reflexões um pouco acima das possibilidades atuais das crianças, mas que sejam motivadoras, atuando na Zona de Desenvolvimento Iminente.

Com o uso desse recurso, constatamos a possibilidade de aquisição de conceitos matemáticos relativos às operações de adição e subtração, pois as crianças modificam seus conhecimentos, tornando-os científicos.

Ressaltamos que os erros cometidos pelas crianças durante o jogo não deixaram marcas negativas, pelo contrário: foram vistos de forma natural e utilizados para reflexões, a respeito de um modo de pensar, permitindo-lhes desenvolverem a autoconfiança em expor suas respostas.

O nosso estudo buscou, dessa forma, contribuir para a aprendizagem de conceitos matemáticos pelo uso de jogos na abordagem histórico-cultural, auxiliando o professor na organização e seleção de atividades de ensino para a apropriação de conceitos, possibilitando a escolha de recursos e situações motivadoras que favoreçam a aprendizagem da criança, tendo como componentes principais a Situação Desencadeadora de Aprendizagem, a Atividade Orientadora de Ensino, as necessidades, os motivos, os objetivos, as condições, os meios, as ações e as operações mentais.

Apesar da nossa intencionalidade e do planejamento cuidadoso das Atividades de Ensino, de modo a possibilitar a formação do pensamento teórico das crianças, temos consciência dos nossos limites. Sabemos que não conseguimos revelar toda a complexidade do objeto estudado, pois compreendemos existirem outros métodos e técnicas que podem ser utilizadas em investigações futuras. Contudo, podemos afirmar 
que este estudo proporcionou-nos elementos para reiterarmos a necessidade e a importância da mediação em situações de ensino, sobretudo as que utilizam jogos para a aquisição de conceitos matemáticos.

Assim, julgamos que os resultados obtidos neste estudo contribuem significativamente não apenas para a nossa aprendizagem, mas também para a compreensão do complexo processo de formação e desenvolvimento das crianças. Igualmente, não podemos deixar de apontar o quanto a concretização deste estudo contribuiu para fortalecer os motivos que impulsionam e orientam nossa prática como docente.

\section{REFERENCIAS}

ASSIS, O. Z. M. et al. Jogar e aprender matemática. São Paulo: LP-Books, 2012.

GIARDINETTO, J. R. B.; MARIANI, J.M. O lúdico no ensino da matemática na perspectiva Vigotskiana do desenvolvimento infantil. In: ARCE, A.; MARTINS, L. M. (Orgs.). Quem tem medo de ensinar na educação infantil? Em defesa do ato de ensinar. Campinas-SP: Alínea, 2007.

KISHIMOTO, T. M. (Org.). Jogo, Brinquedo, Brincadeira e a Educação. 4 ed. São Paulo: Editora Cortez, 2000.

LÁZARO, C. A.; TANAKA, G. C.; RODRIGUES, T. M. Jogos no Ensino de Matemática: experiências com o - fecha a caixa. Repositório Institucional UNESP, Bauru, Departamento de Matemática, Faculdade de Ciências, 2013. Disponível em: <http://repositorio.unesp.br/handle/11449/135151>. Acesso em: 12 fev. 2015.

LURIA. Desenvolvimento cognitivo: seus fundamentos culturais e sociais. Tradução de Luiz Mena Barreto e Marta Kohl Oliveira. São Paulo: Ícone, 1994.

MORETTI, V. D.; SOUZA, N. M. M. Educação matemática nos anos iniciais do ensino fundamental: Princípios e práticas pedagógicas. 1. ed., São Paulo: Cortez, 2015.

MOURA, M. O. de. O jogo e a construção do conhecimento matemático. Ideias, São Paulo, n. 10, p. 45-53, 1991.

MOURA, M. O. et al. A atividade orientadora de ensino como unidade entre ensino e aprendizagem. In: MOURA, M. O. (Org.). A atividade pedagógica na teoria histórico cultural. Brasília: Liber Livro, 2010, p.81-109.

NACANALLO, L. F.; MORI, N. N. R. Jogos em matemática: uma possibilidade de desenvolvimento de funções psicológicas superiores. In: SEMINÁRIO DE PESQUISA, 2008, Londrina. Anais... Londrina, 2008. Disponível em: 
<www.ppe.uem.br/publicacoes/seminario_ppe_2008/pdf/c025.pdf >. Acesso em: 06 set. 2015.

NUNES, T. et al. Educação matemática: números e operações numéricas. 2. ed. São Paulo: Cortez, 2009.

PONTE, J. P. Estudos de caso em Educação Matemática. Bolema, n. 25, p. 105-132, 2006. Disponível em: <http://repositorio.ul.pt/bitstream/10451/3007/1/06Ponte\%28BOLEMAEstudo\%20de\%20caso\%29.pdf>. Acesso em: 30 ago. 2015.

VIGOTSKY, L.S. A construção do pensamento e da linguagem. Tradução de Paulo Bezerra. São Paulo: Martins Fontes, 2009.

\section{Como referenciar este artigo}

PEREIRA, Patrícia. Jogos Matemáticos e Mediação Docente. Revista on line de Política e Gestão Educacional, Araraquara, v.21, n.3, p. 1484-1498, set./dez., 2017. ISSN: 1519-9029.

Submetido em: 20/08/2017

Aprovado em: 30/11/2017 